\title{
Smart Door Control System
}

\author{
Akash S Devadiga $^{1}$, Adithya $^{2}$, Abhilash $^{3}$, Hithesh $^{4}$ \\ Student, ECE, SMVITM Bantakal, Udupi, India ${ }^{1,2,3,4}$
}

\begin{abstract}
The major activity that takes place around world is automation and security. The automation or remote control has become fundamental to our lives .The project presented here is a novel approach towards automation and security. In this project, we present the design and implementation of a GSM based wireless home/office/other area security system. And this system helps for people with physical disabilities. Here the system automatically controls (open or close) the door as soon it receives predefined message from the user. The system mainly consisting of microcontroller, GSM and gear motor for controlling the door. The door is controlled only by the authorized persons through sending control SMS to the GSM module. If unauthorized person wants to access the door then, he has to press call button which is kept beside the door then, automatic voice call going to authorized person, thus user can communicate with the unauthorised person lively. If he wants to open the door he can send door open SMS to the device, then door will starts opening and after some time authorized person can close the door remotely by sending another SMS. The door is controlled via H-bridge circuit. If intruder tries to enter the door forcefully, then door sensor is activated it gives signal to microcontroller and alert message is goes to authorized person.
\end{abstract}

Keywords: GSM, PIC microcontroller, H-bridge, Gear motor, PIR, Door sensor logic, LCD.

\section{INTRODUCTION}

Now a days there is a need of highly secured and automated systems for security purpose the problems being, robbery and other security issues which are increasing day by day, proving to be an increasing threat for human life. In residential areas even after providing facilities such as security guard, there seems to be no solution to these problems. In 2010, the Federal Bureau of Investigation (FBI) reports that there were more than two million home burglaries in the United States, over 70 percent of which took place in residential homes. According to 2011 reports by National Crime Records Bureau (NCRB), in India, the number of burglary cases registered was 58862 cases, with a total worth of USD 50 million. According to a 2010 study by the Alarm Industry Research and Educational Foundation (AIREF), burglars spend less than 60 seconds for breaking into a home. So, anything that made a house harder to access, including home security systems, deadbolt locks, bars on windows, acted as a deterrent. Further, according to the Electronic Security Association's (ESA) "Home Safety Fast Facts" report, 9 out of 10 burglars avoid homes with alarm systems and said if they did encounter an alarm, they would not attack the home and drop the attempt. These facts have encouraged the development of numerous security systems for both residential and commercial applications. This system is mainly focus on automation and security and this system very helpful for physical disable people.

\section{METHODOLOGY}

This project is aimed to design a system using which the door can be automated i.e. it can be opened and closed automatically by using GSM technology. A GSM modem provides the communication interface. It transports device protocols transparently over the network through a serial interface. A GSM modem is a wireless modem that works with a GSM wireless network. This GSM Modem can accept any GSM network operator SIM card and act just like a mobile phone with its own unique phone number. Advantage of using this modem will be that you can use its RS232 port to communicate and develop embedded applications. Applications like SMS Control, data transfer, remote control and logging can be developed easily. The modem can either be connected to PC serial port directly or to any microcontroller. This project is designed in such a way that a GSM modem will be interfaced to the controller through serial port interface along with the DC motor through voltage driver IC L293D. The door is connected to this motor. The microcontroller will be programmed in such a way that some predefined messages will be assigned to the controller for controlling the motor in different directions i.e. opening and closing of the door. Whenever the user wants to control the door, he has to send predefined messages to the modem. When the modem receives data (SMS), it will intimate the same to the microcontroller. Now, it is the job of the controller performs the predefined task of controlling the door in clockwise or anticlockwise in accordance with the message received from the modem. A $16 \mathrm{X} 2 \mathrm{LCD}$ will be interfaced to the controller to display the status of the door. This project uses regulated 12V, 1A power supply. 7805 three terminal voltage regulator is used for voltage regulation. Full wave bridge rectifier is used to rectify the ac output of secondary of $230 / 12 \mathrm{~V}$ step down transformer. 
IJIREEICE

International Journal of Innovative Research in Electrical, Electronics, Instrumentation and Control Engineering

ISO 3297:2007 Certified

Vol. 5, Issue 6, June 2017

III.WORKING

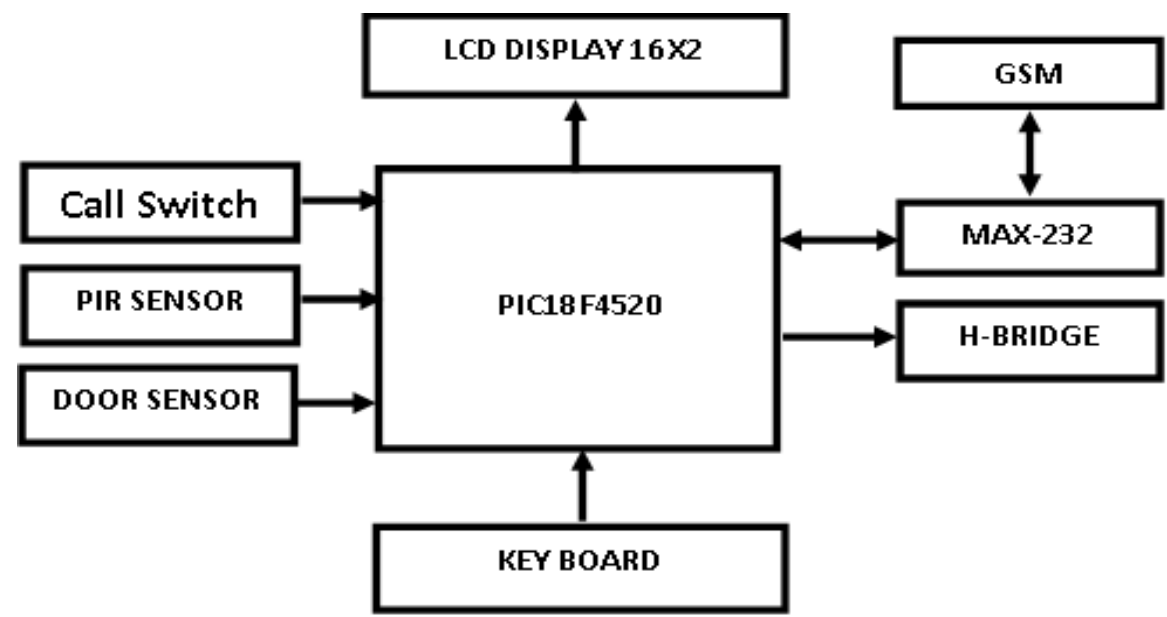

Figure1: Block diagram of proposed system.

When we switch ON the system, after certain delay that is 10 seconds, the system gets initialized and microcontroller starts reading the other devices input at the rate of $20 \mathrm{~ms}$ per channel. The function of proposed project in various parts has been explained bellow:

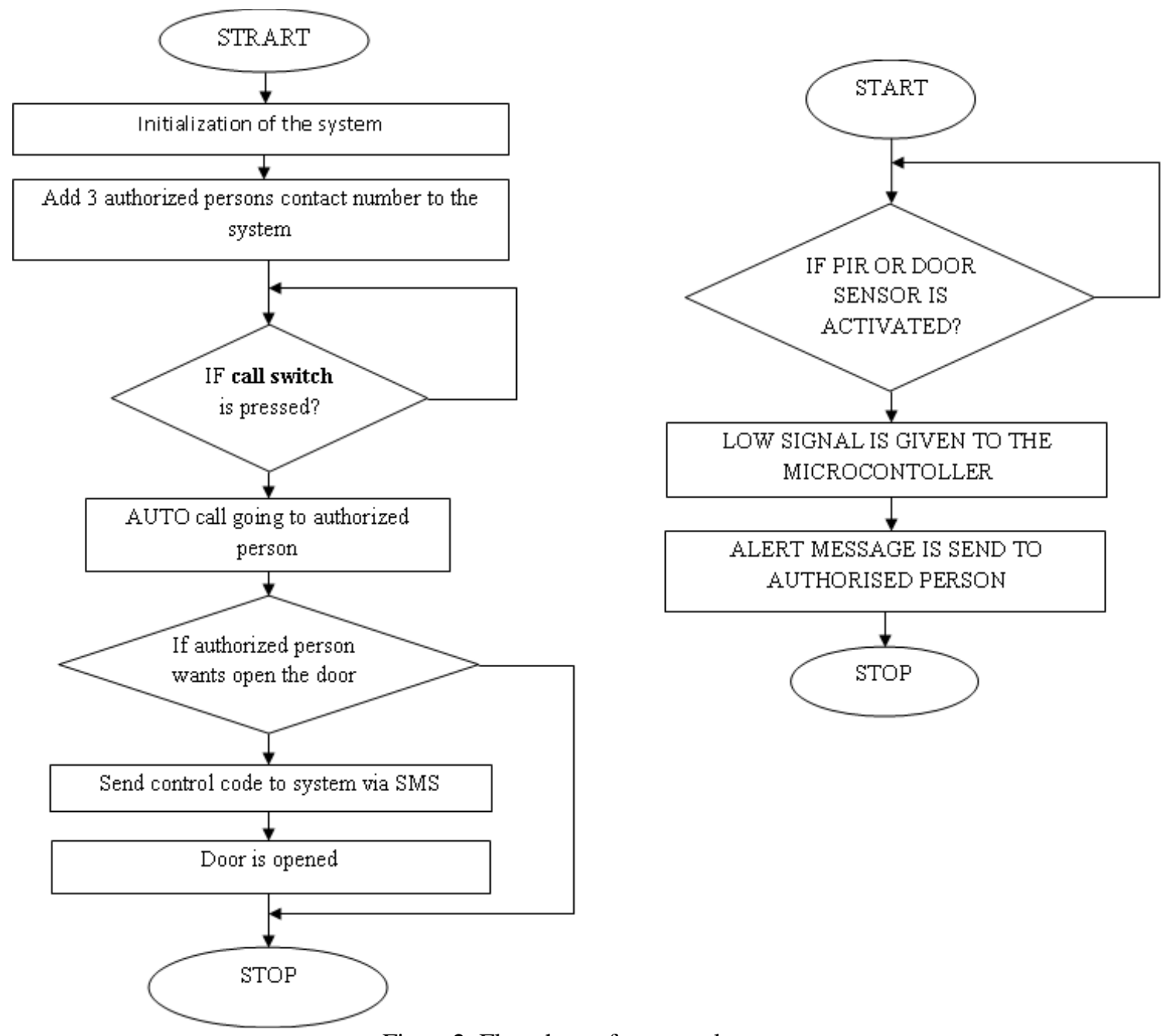

Figure2. Flowchart of proposed system 
The first and most important part of project is providing security. The main door is controlled through SMS. When an authorized person tries to enter the door, all he has to send a SMS to GSM modem. When an unauthorized person is comes, the PIR sensor is activated it gives signal to microcontroller, and microcontroller send a alert message to authorized person via GSM modem. The unauthorized person wants to access the door he has to press call button then, automatic voice call going to authorized person, thus user can communicate with the intruder lively. If he wants to open the door he can send door open SMS to the device, then door will starts opening and after some time authorized person can close the door remotely by sending another SMS. The door is controlled via H-bridge circuit. If intruder tries to enter the door forcefully, then door sensor is activated it gives signal to microcontroller and alert message is goes to authorized person.

\section{HARDWARE IMPLIMENTATION}

The hardware of system the system mainly consisting of following components:

- PIC microcontroller 18F4520.

- GSM SIM900.

- Gear motor.

- MAX232 (RS232).

- H-BRIDGE circuit.

- Liquid Crystal Display (LCD).

- Crystal Oscillator.

- Power supply.

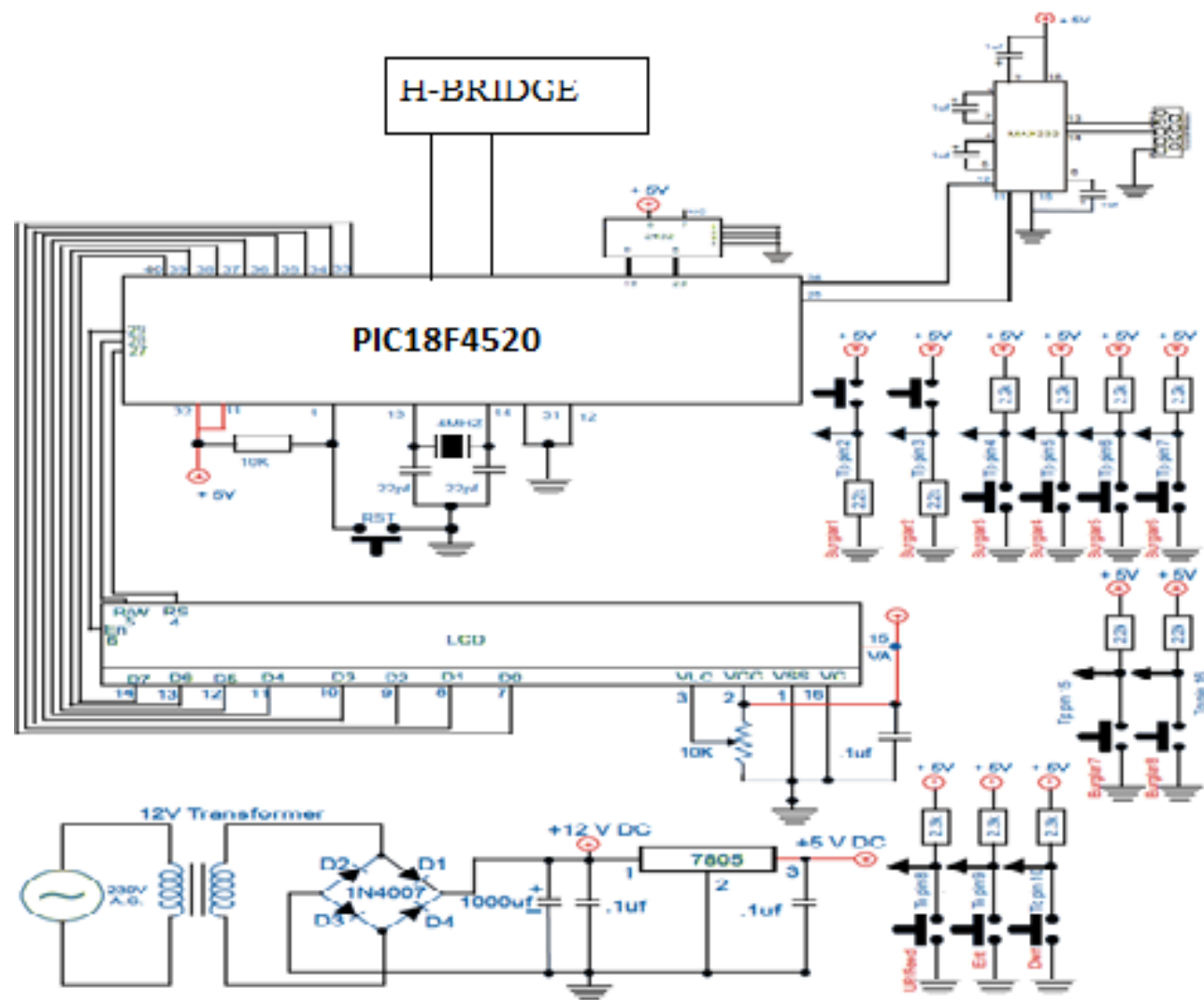

\section{GSM MODULE}

Figure3. Circuit Diagram of Proposed System

A. PIC Micro controller

PIC 18F4520 is the main controller in this system, which controls the all the operations of the system. It consists of $32 \mathrm{~KB}$ of program memory and 40 pins (there are 33 bidirectional I/O pins).

B. GSM

GSM is known as Global System for Mobile Communication. A technology developed in 1985 by a French company 
known as Group Special Mobile. The door is controlled through sending short message service to GSM. And live communication takes place between authorised and unauthorised persons using GSM module.

C. MAX232

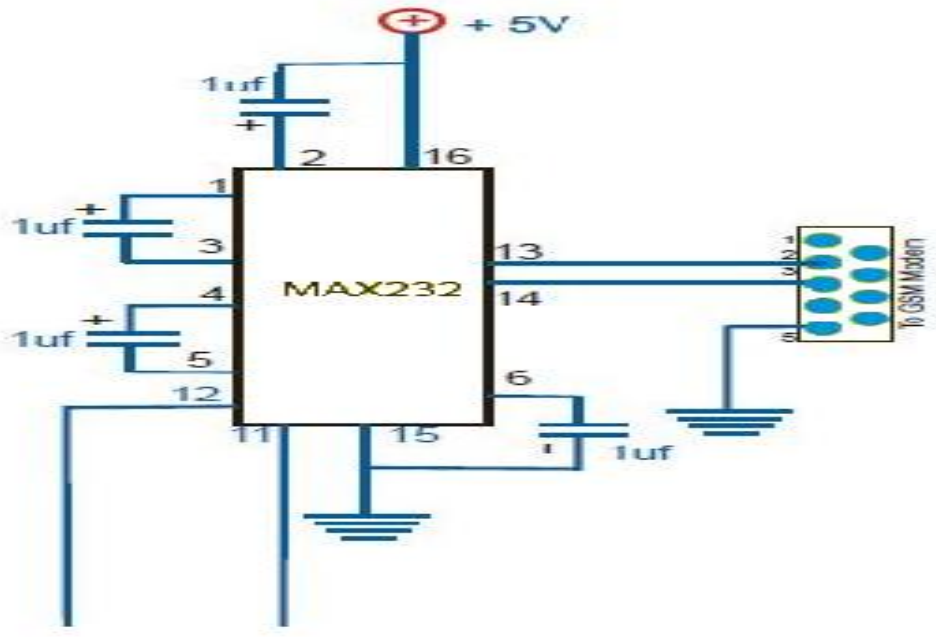

Figure4. MAX 232 circuit

The MAX232 is the level converter. It is mainly used to communication between microcontroller and GSM module. The MAX 232 is an integrated circuit that converts signals from an RS-232 serial port to signals suitable for use in TTL compatible digital logic circuits. The MAX232is a dual driver/receiver and typically converts the RX, TX, CTS and RTS signals.

\section{CRYSTAL OSCILLATOR}

A crystal oscillator is an electronic oscillator circuit that uses the mechanical resonance of a vibrating crystal of piezoelectric material to create an electrical signal with a very precise frequency. This frequency is commonly used to keep track of time (as in quartz wristwatches), to provide a stable clock signal for digital integrated circuits, and to stabilize frequencies for radio transmitter and receivers. In our project we use 11.059MHertz frequency.

\section{E. GEAR MOTOR}

A gear motor is a specific type of electrical motor that is used to control the door open or close and it is designed to produce high torque while maintaining a low Horse power, or low speed, motor output. Gear motors can be found in many different applications, and are probably used in many devices in your home.

\section{F. H-BRIDGE}

A D.C. Motor requires a voltage difference between its terminals to rotate. The direction in which a motor rotates in determined by which side of the motor is connected to the positive and negative terminals. Swapping the positive and negative terminals will cause the motor to rotate in the opposite direction. An H-Bridge is used to control the direction of the motor and to also provide enough current for the motor to run.

\section{G. LCD}

LCD (Liquid Crystal Display) screen is an electronic display module and find a wide range of applications. A 16x2 LCD display is very basic module and is very commonly used in various devices and circuits. These modules are preferred over seven segments and other multi segment LEDs. The reasons being: LCDs are economical; easily programmable; have no limitation of displaying special \& even custom characters (unlike in seven segments), animations and so on.

\section{H. POWER SUPPLY}

Two transformers are used in this section to powering the Micro Controller section and MAX232, GSM section, and Sensor section. These two transformers are used to step down the 220 volts A.C mains supply into 12 volts A.C supply. Current handling capacity of the transformer is $500 \mathrm{ma}$. The primary resistance of the transformer is about 700 ohms, secondary resistance is about 4 ohms. 


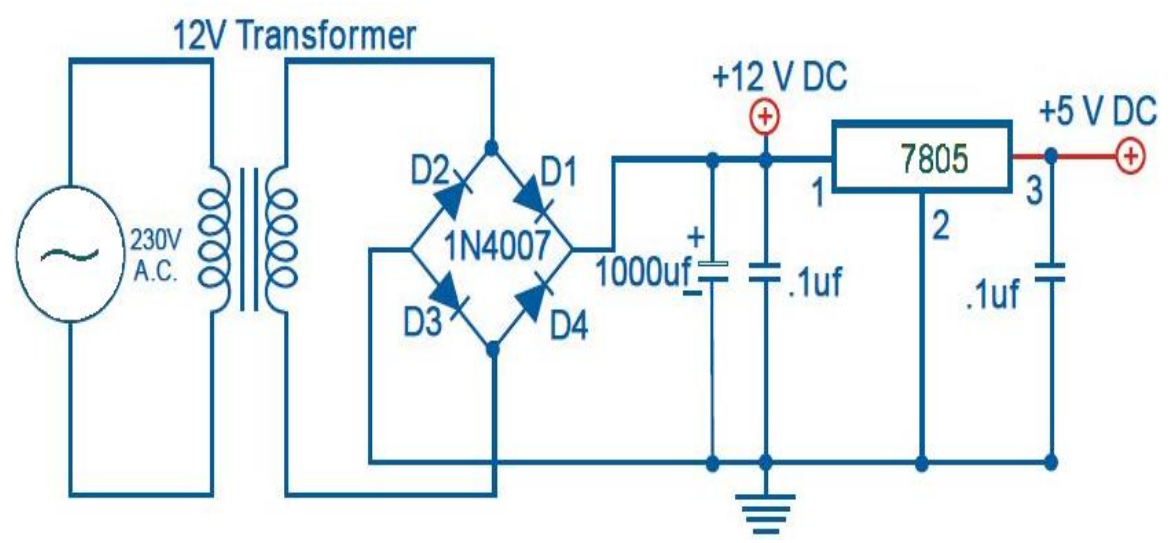

Figure5. Power supply circuit

\section{SOFTWARE CONFIGURATION}

The software is written in a combination of Basic and Assembler using the PIC Simulator MPLAB IDE. A super fine development tool. The Basic in the simulator includes commands for communicating through the serial port on the PIC, but there is no error handling in the receiver routine and to ensure full stability in the software a new receive routine has been written in assembler (this is based on the studio of PIC hardware serial port written in PICUART.ASM document. You can find it on the net too). Rest of the code is written in Basic so it is straight forward to debug.

After initializing the modem (the software check for a respond from the modem before trying to do further communication) the software reads the phone number from the SIM card and stores it in local memory. After this it goes into a loop checking the inputs incl. power and very 10 seconds checking for a new inputs.

If an input is activated the phone number is read from memory and send to the modem followed by the messages. If a new SMS is received the modem will store it in position 1 if free otherwise it will be stored on the first free location. By clearing the first position we ensure that any new message will be stored here. This simplifies the software as it only needs to check for new message on this position. If a new message has arrived it will be read, decoded and deleted.

The decoding part checks that the pin code in the message is identically with the last four digits of the phone number. If ok the included command is executed. Polling the modem every 10th second is simple method but it has a disadvantage. If the system receives two new messages in a row it will only be able to handle the first one and the other one will be lost. Due to this you should disable any 'service information' from your GSM operator to limit the amount of crappy SMS received. If you send a command to the system and you don't get at respond within a minute, then just resend it.

For this simple setup only four commands are implemented: Two for switching the output ON/OFF, two for enable/disable the inputs and one for asking for status for the output.

\section{VI.ADVANTAGES AND DISADVANTAGES}

\section{A. ADVANTAGES}

- Remote indication: With the use of GSM technology owner of the house or industry get remote indication through SMS. So even if the user is away from home or industry, he/she will be intimated about the hazardous or undesirable conditions / situations inside the house.

- This system is fully automated. So once this system is installed inside home or industry, then it does not require any human interaction to operate.

- No complex in design.

- This system is Cost effective. Also it is Fast and efficient.

B. DISADVANTAGES

- If network is not there then system cannot accessed.

\section{RESULT}

\section{A. Initialization of system}

When we switch ON the system, after certain delay that is 10 seconds, the system gets initialized and microcontroller starts reading the other devices input at the rate of $20 \mathrm{~ms}$ per channel. 


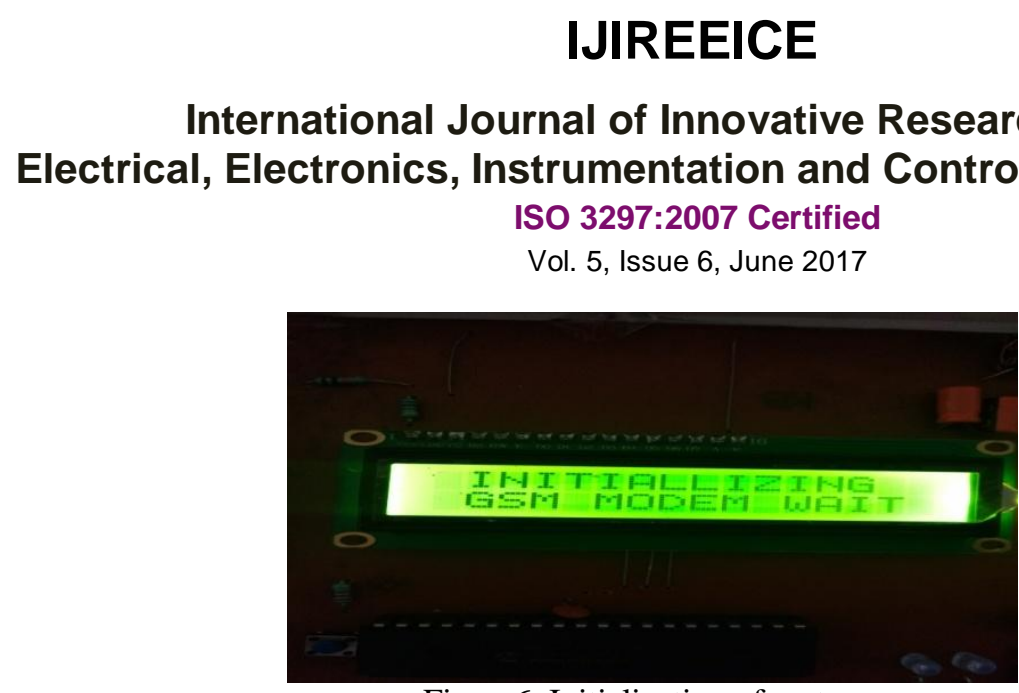

Figure6. Initialization of system.

B. Call switch processing

If unauthorised person wants to access the door, he has to call to authorised person by pressing call switch, then live communication takes place between unauthorised and authorised persons.

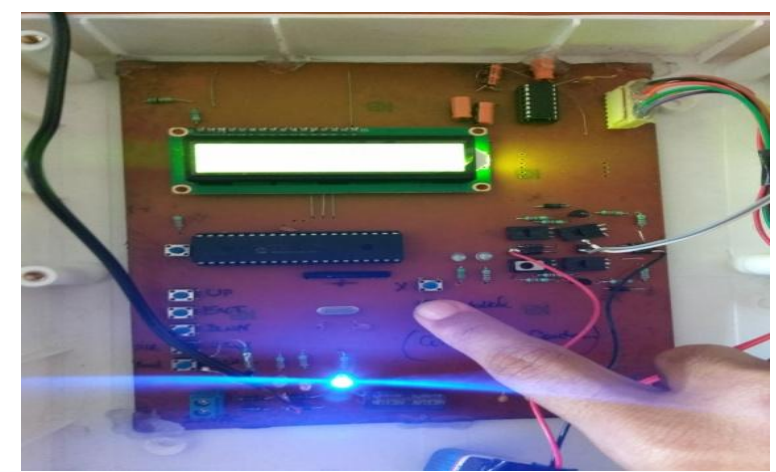

Figure7. Call switch processing.

C. AUTO CALL DIALLING

After pressing call switch then automatic call is going to the authorised person.

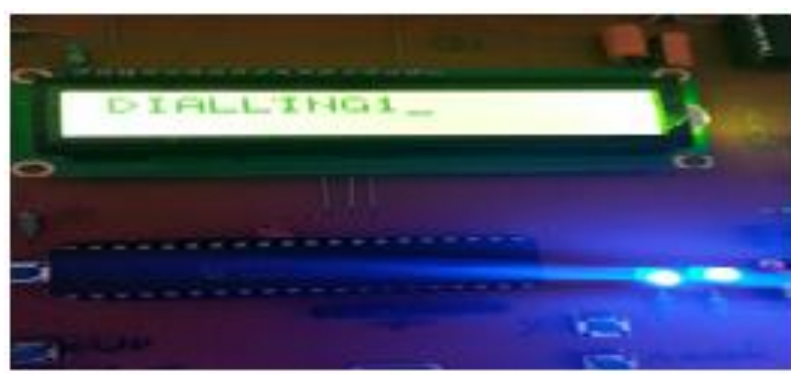

Figure8. Automatic call dialing.

D. DOOR ACCESSING

If authorised person wants to access the door, he will send control message to GSM Then door is opened or closed.

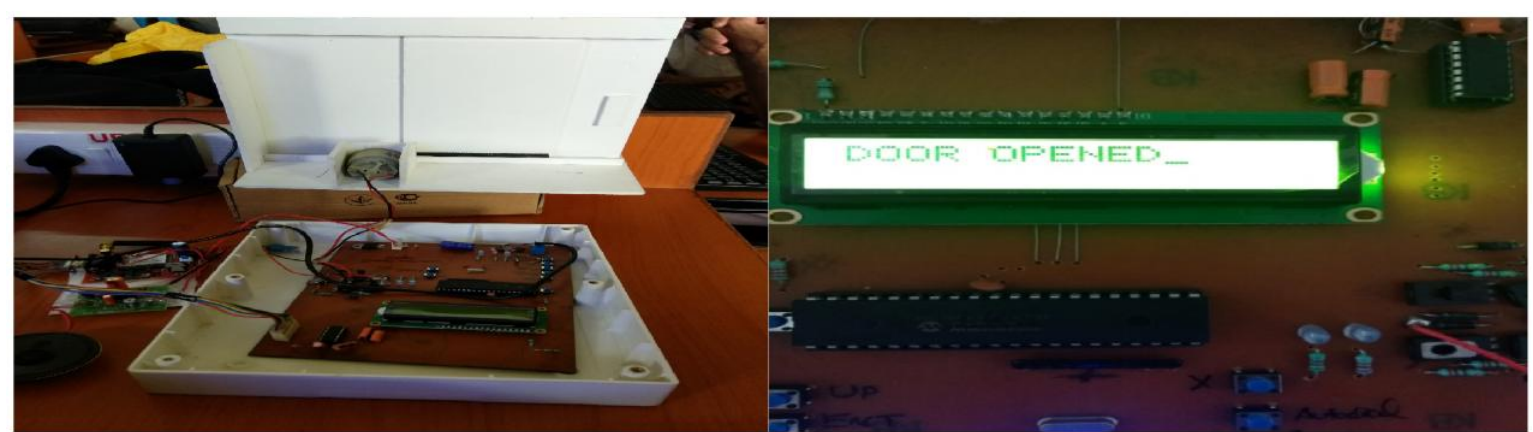

Figure9. Door accessing via SMS. 


\section{CONCLUSION AND FUTURE SCOPE}

The GSM Based Digital Door Lock Security System was designed and implemented successfully. On basis of detailed analysis and trials, we could conclude that the system was stable and can be an emerging product in field of security systems residential and commercial applications. We suggest following improvements in future development of system

1) Integrating with face detecting sensors.

2) Integrating with gesture sensors.

3) Interfacing with CCTV network.

4) Integrating with $3 \mathrm{D}$ holographic password input keyboard.

5) Integrating with multiple locks on multiple doors inside a facility.

6) Replacing motors with pneumatic valves.

7) Addition of a lock tampering detection system.

8) Addition of backup battery supply to facilitate uninterrupted service.

\section{ACKNOWLEDGMENT}

I express my deep sense of gratitude and indebtedness to our institution "SHREE MADWA VADIRAJA INSTITUTE OF TECHNOLOGY AND MANAGEMENT, VTU UNIVERSITY, which provided me the opportunity to fulfill our cherished goals. I extend my sincere thanks and regards to lecturers for giving us this opportunity to carry out this work in the college. I sincerely acknowledge the encouragement and support given to us by our guide Mrs. RAJASHREE NAMBIAR Associate professor, dept. of ECE, SMVITM \& project coordinator Mr. SACHIN BHAT, Associate professor, dept. of ECE, SMVITM. I would most heartily like to thank the almighty, my family members and friends without whom this paper would be impossible.

\section{REFERENCES}

[1]. Chi-Huang Hung; Ying-Wen Bai; Je-Hong Ren "Design and implementation of a single button operation for a door lock control system based on a near field communication of a smart phone" Consumer Electronics - Berlin (ICCE-Berlin), 2015 IEEE 5th International Conference on Year - 2015

[2]. Xi Zeng; Guo-jun Zhao; Yuan-ping Wang; Chao-rong Wang; Jun-hui Wang "Research on the Elevator Door Control System Based on the Image Processing Technology" Electrical and Control Engineering (ICECE), 2010 International Conference on Year: 2010

[3]. Chih-Min Lo; Sun-Jen Huang "Embedded control system development using UML for automatic doors" SICE Annual Conference 2010, Proceedings of Year: 2010

[4]. Mrutyunjaya Sahani; Chiranjiv Nanda; Abhijeet Kumar Sahu; Biswajeet Pattnaik "Web-based online embedded door access control and home security system based on face recognition" Circuit, Power and Computing Technologies (ICCPCT), 2015 International Conference on Year: 2015

[5]. A. Aditya Shankar et al., "Finger Print Based Door Locking System", International Journal Of Engineering And Computer Science, Volume 4 Issue 3 March 2015, pp. 10810-10814.

\section{BIOGRAPHIES}

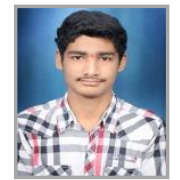

AKASH S DEVADIGA is a student in the Department of Electronics and Communication Engineering, Shree Madwa Vadiraja Institute of Technology and Management, Udupi, Karnataka. He is pursuing Bachelor degree in Electronics \& Communication Engineering from VTU University, Karnataka, India.

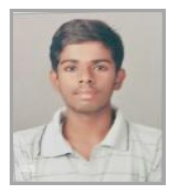

ADITHYA is a student in the Department of Electronics and Communication Engineering, Shree Madwa Vadiraja Institute of Technology and Management, Udupi, Karnataka. He is pursuing Bachelor degree in Electronics \& Communication Engineering from VTU University, Karnataka, India.

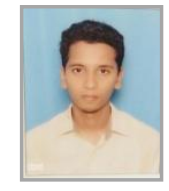

ABHILASH is a student in the Department of Electronics and Communication Engineering, Shree Madwa Vadiraja Institute of Technology and Management, Udupi, Karnataka. He is pursuing Bachelor degree in Electronics \& Communication Engineering from VTU University, Karnataka, India.

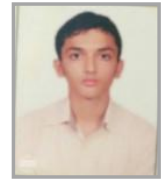

HITHESH is a student in the Department of Electronics and Communication Engineering, Shree Madwa Vadiraja Institute of Technology and Management, Udupi, Karnataka. He is pursuing Bachelor degree in Electronics \& Communication Engineering from VTU University, Karnataka, India. 